\title{
Upregulation of TRPM7 augments cell proliferation and interleukin-8 release in airway smooth muscle cells of rats exposed to cigarette smoke
}

\author{
XIAOLING LIN ${ }^{1 *}$, CHENG YANG $^{2 *}$, LINJIE HUANG ${ }^{1}$, MING CHEN $^{1}$, JIANTING SHI $^{1}$, LIHUA OUYANG ${ }^{1}$, \\ TIANTIAN TANG ${ }^{1}$, WEI ZHANG ${ }^{1}$, YIQUN LI ${ }^{1}$, RUIYUN LIANG ${ }^{1}$ and SHANPING JIANG ${ }^{1}$ \\ ${ }^{1}$ Department of Respiratory Medicine, Sun Yat-Sen Memorial Hospital, \\ Institute of Respiratory Disease, Sun Yat-Sen University, Guangzhou, \\ Guangdong 510120; ${ }^{2}$ Department of Respiratory Medicine, Meizhou People's Hospital, \\ Meizhou Affiliated Hospital of Sun Yat-Sen University, \\ Meizhou, Guangdong 514031, P.R. China
}

Received May 13, 2015; Accepted March 10, 2016

DOI: $10.3892 / \mathrm{mmr} .2016 .5161$

\begin{abstract}
Proliferation and synthetic function (i.e. the capacity to release numerous chemokines and cytokines) of airway smooth muscle cells (ASMCs) are important in airway remodeling induced by cigarette smoke exposure. However, the molecular mechanism has not been clarified. Transient receptor potential cation channel subfamily $\mathrm{M}$ member 7 (TRPM7) is expressed ubiquitously and is crucial for the cellular physiological function of many cell types. The present study aimed to detect the expression of TRPM7 in ASMCs from smoke-exposed rats and determine the importance of TRPM7 in proliferation and interleukin-8 (IL-8) release. ASMCs were isolated and cultured from smoke-exposed rats. Expression levels of TRPM7 were determined by reverse transcription-polymerase chain reaction, western blot analysis and immunofluorescence. TRPM7 was silenced with TRPM7-short hairpin RNA lentivirus vector. DNA synthesis, cell number and IL- 8 release of ASMCs induced by cigarette smoke extract (CSE) and tumor necrosis factor- $\alpha$ (TNF- $\alpha$ ) were assessed using $\left[{ }^{3} \mathrm{H}\right]$-thymidine incorporation assay, hemocytometer and enzyme-linked immunosorbent assay, respectively. It was determined that mRNA and
\end{abstract}

Correspondence to: Professor Ruiyun Liang or Professor Shanping Jiang, Department of Respiratory Medicine, Sun Yet-Sen Memorial Hospital, Institute of Respiratory Disease, Sun Yet-Sen University, 107 Yan Jiang West Road, Guangzhou, Guangdong 510120, P.R. China E-mail: liangruiyun@yahoo.com.cn

E-mail: shanpingjiang@126.com

*Contributed equally

Key words: airway smooth muscle cell, transient receptor potential melastatin 7 , cigarette smoke exposure, cell proliferation, interleukin- 8 protein expression levels of TRPM7 were increased in ASMCs from smoke-exposed rats. Stimulation with CSE or TNF- $\alpha$ elevated DNA synthesis, cell number and IL- 8 release were more marked in ASMCs from smoke-exposed rats. Silencing of TRPM7 reduced DNA synthesis, cell number and IL- 8 release induced by CSE or TNF- $\alpha$ in ASMCs from smoke-exposed rats. In conclusion, expression of TRPM7 increased significantly in ASMCs from smoke-exposed rats and the upregulation of TRPM7 led to augmented cell proliferation and IL- 8 release in ASMCs from rats exposed to cigarette smoke.

\section{Introduction}

Chronic obstructive pulmonary disease (COPD) is characterized by persistent and progressive airflow limitation, which is associated with chronic airway inflammation and parenchymal destruction (1). When exposed to chronic irritants such as cigarette smoke (a common risk factor of COPD) repeated injury and repair, and chronic inflammatory response of the airway wall result in structural changes termed airway remodeling (2,3). Airway smooth muscle (ASM) is one of the important structures of airway wall, and contributes to the chronic inflammatory response and airway remodeling in COPD due to its proliferation and synthetic capabilities (4).

Many cytokines, chemokines and growth factors promote ASM cell (ASMC) proliferation (5) and exposure to cigarette smoke extract (CSE) induces a proliferative phenotype of cultured ASMCs (6). In addition, ASMCs provide cytokines in the airway by releasing eotaxin, chemokine (C-C motif) ligand 5, monocyte chemoattractant proteins, interleukin-6 (IL-6) and IL-8 (7). Pro-inflammatory cytokines, such as tumor necrosis factor- $\alpha$ (TNF- $\alpha)$, and CSE lead to increased expression of various cytokines from $\operatorname{ASM}(8,9)$. The release of IL-8, an important neutrophil chemoattractant, from ASMCs and inflammatory cells is important in the pathogenesis of COPD (10). However, the underlying mechanisms of 
ASM proliferation and synthetic function induced by cigarette smoke exposure have not been elucidated.

Although a wide variety of ion channels are expressed in ASMCs to regulate its biological activities, the precise function of the majority of channels requires investigation. Transient receptor potential cation channel subfamily $M$ member 7 (TRPM7) is a non-selective ion channel permeable to various divalent cations (such as $\mathrm{Mg}^{2+}$ and $\mathrm{Ca}^{2+}$ ) with a distinctive serine/threonine protein kinase domain in its C-terminal (11-13). This channel is highly expressed in the brain, heart, liver, kidney and lung of mammals $(14,15)$ and it has been determined that TRPM7 is important for cellular survival and proliferation of numerous cell types (16). Additionally, in our previous study, it was identified that inhibition of TRPM7 reduced the release of cytokines in rat bone marrow-derived mast cells (17). However, to the best of our knowledge, the association between TRPM7 and ASM with cigarette smoke exposure has not previously been investigated. The aim of the present study was to detect the expression of TRPM7 in ASMCs from rats exposed to cigarette smoke. Furthermore, the role of TRPM7 in cell proliferation and IL-8 release was investigated in the ASMCs.

\section{Materials and methods}

Animals. A total of 24 five- to six-week-old male Sprague-Dawley (SD) rats (weight, 150-180 g) were obtained from the Laboratory Animal Center of Sun Yat-sen University (Guangdong Experimental Animal Testing, Guangzhou, China; certificate no. 0101668). The rats were housed in a temperature-controlled room $\left(26 \pm 1^{\circ} \mathrm{C}\right)$ and maintained on a 12-h light/dark cycle with free access to water and food. All the experiments described were performed in accordance with the regulations of the Centre of Animal Experiments of Sun Yat-sen University. Ethical approval for this investigation was obtained from the Research Ethics Committee, Sun Yat-sen University (Guangzhou, China).

Cigarette smoke exposure. The rats were randomly divided into the smoke-exposed group and control groups $(n=12)$. The rats of the smoke-exposed group were placed in a plastic chamber and exposed to $3 \mathrm{R} 4 \mathrm{~F}$ research cigarette smoke (University of Kentucky, Lexington, KY, USA), one cigarette twice a day, with one day off every week, for 90 days. The control rats were placed in another plastic chamber and exposed to fresh air over the same time period. All rats were sacrificed by cervical dislocation following $\mathrm{CO}_{2}$ narcosis after the 90-day period for CSE (or fresh air for the control group) was completed. CSE was prepared by burning two 3R4F research cigarettes without a filter and passing the smoke to a $50 \mathrm{ml}$ conical tube containing $20 \mathrm{ml}$ culture medium (Guangzhou Whiga Technology Co., Ltd., Guangzhou, China) at a rate of $5 \mathrm{~min} /$ cigarette. The obtained solution was filtered through a $0.22-\mu \mathrm{m}$ filter and was referred to as $100 \%$ strength CSE.

Lung histology and immunohistochemical staining. Lung tissue samples $(5 \mu \mathrm{m})$ of right lobe was removed from the rats. The tissue samples were fixed with $10 \%$ neutral buffered formalin (Guangzhou Whiga Technology Co., Ltd.) and the specimens were dehydrated (by incubating sequentially for $2 \mathrm{~h}$ in $75 \%, 85 \%, 95 \%$ and $100 \%$ alcohol, in turn) and embedded in paraffin (Guangzhou Whiga Technology Co., Ltd.). Fixed embedded tissue sections (size, $5 \mu \mathrm{m}$ ) were sliced, placed on glass slides and deparaffinized. Subsequently, $\alpha$-smooth muscle actin immunohistochemical staining with monoclonal mouse anti- $\alpha$-smooth muscle actin antibody (1:100; Thermo Fisher Scientific, Inc., Waltham, MA, USA) was used to determine smooth muscle cells in the lung. The ASM areas were stained brown as a result of the $\alpha$-smooth muscle actin immunohistochemical staining. The ASM areas $\left(\mu \mathrm{m}^{2}\right)$ of eight independent bronchioles were measured using Image-Pro Plus version 6.0 software (Media Cybernetics, Inc., Rockville, MD, USA). The results are expressed as a proportion of the total airway area [i.e. the lumen plus the airway wall for the external area at the adventitial border $\left.\left(\mu \mathrm{m}^{2}\right)\right]$.

Isolation and culture of ASMCs. ASMCs were obtained from the trachea and bronchi of smoke-exposed and control SD rats as previously described $(18,19)$. Briefly, the trachea and main bronchi were removed and separated from the lung, bronchial vessels and connective tissue, then dissected into cubes (dimension, 1x1x1 mm). All segments were cultured with Gibco Dulbecco's modified Eagle's medium (DMEM; Thermo Fisher Scientific, Inc.) supplemented with $20 \%$ fetal calf serum (FCS; Gibco; Thermo Fisher Scientific, Inc.), $100 \mathrm{U} / \mathrm{ml}$ penicillin (Guangzhou Whiga Technology Co., Ltd., Guangzhou, China) and $100 \mathrm{mg} / \mathrm{ml}$ streptomycin (Guangzhou Whiga Technology Co., Ltd.) in conditions of $37^{\circ} \mathrm{C}$ and $5 \% \mathrm{CO}_{2}$ for 5 days. Cells were grown to $80 \%$ confluence (observed under an inverted phase contrast microscope; Leica Microsystems Wetzlar GmbH, Wetzlar, Germany), the medium was removed, the explants were washed twice with Gibco Hank's Balanced Salt Solution (Thermo Fisher Scientific, Inc.) and trypsinized (in $1 \mathrm{ml}$ of a $0.25 \%$ trypsin solution; Guangzhou Whiga Technology Co., Ltd.) for 1 min. Next, ASMCs were cultured in DMEM medium supplemented with penicillin and streptomycin at the above-mentioned concentrations and 10\% FCS. The medium was replaced every 2 days. ASMCs were identified by the characteristic hill-and-valley appearance and $\alpha$-smooth muscle actin immunocytochemical staining. Experiments were performed on freshly isolated ASMCs.

Immunocytochemistry. ASMCs were identified by $\alpha$-smooth muscle actin immunocytochemical staining, as previously described $(18,19)$. Briefly, ASMCs were seeded onto sterile glass coverslips and grown to $70 \%$ confluence. Cells were fixed in $4 \%$ paraformaldehyde for $20 \mathrm{~min}$, and the sections were reacted with $3 \% \mathrm{H}_{2} \mathrm{O}_{2}$ (Guangzhou Whiga Technology Co., Ltd.) After a rinse in phosphate-buffered saline (PBS), the sections were blocked with $2 \%$ bovine serum albumin (BSA; Guangzhou Whiga Technology Co., Ltd.) and incubated with monoclonal mouse anti- $\alpha$-smooth muscle actin antibody (1:300; Thermo Fisher Scientific, Inc.) at $4^{\circ} \mathrm{C}$ overnight for immunolabeling. Subsequently, the sections were incubated with a secondary horseradish peroxidase (HRP)-conjugated rabbit anti-mouse IgG (1:300; Cell Signaling Technology, Inc., Danvers, MA, USA) for $30 \mathrm{~min}$ at $37^{\circ} \mathrm{C}$ and then washed three times with PBS. The peroxidase activity was visualized by a color reaction using 3,3'-diaminobenzidine (1 ml; Wuhan 
Boster Biological Technology, Ltd., Wuhan, China) as the substrate. The slides were then counterstained with hematoxylin (Wuhan Boster Biological Technology, Ltd.), mounted and examined under a microscope (Olympus Corp., Tokyo, Japan) using AxioVision 4.1 software (Carl Zeiss Microscopy, LLC, Thornwood, NY, USA).

Reverse transcription-polymerase chain reaction (RT-PCR). Total RNA was extracted from ASMCs according to the instructions of the TRIzol Reagent kit (Invitrogen; Thermo Fisher Scientific, Inc.). RT-PCR was performed using the SuperScript One-step RT-PCR system (Invitrogen; Thermo Fisher Scientific, Inc.) according to the manufacturer's protocol. There were 35 cycles of $90^{\circ} \mathrm{C}$ for $35 \mathrm{sec}, 56^{\circ} \mathrm{C}$ for $30 \mathrm{sec}$ and $72^{\circ} \mathrm{C}$ for $30 \mathrm{sec}$. $\beta$-actin served as an internal control. The primers were as follows: Forward, 5'-CTGAAG AGGAATGACTACAC-3' and reverse, 5'-ACAGGAAAA AGAGAGGGAG-3' for TRPM7 [(GenBank, AC000071) Invitrogen; Thermo Fisher Scientific, Inc.]; forward, 5'-TGA GCTGCGTGTGGCCCCTGAG-3' and reverse, 5'-GGG GCATCGGAACCGCTCATTG-3' for $\beta$-actin [(GenBank, AC000080) Applied Biosystems; Thermo Fisher Scientific, Inc.].

Western blot analysis. ASMCs were lysed with radioimmunoprecipitation assay lysis buffer (Beyotime Institute of Biotechnology, Shanghai, China). The extracts were collected and protein concentrations were measured using a bicinchoninic acid protein assay kit (Wuhan Boster Biological Technology, Ltd.). Equal quantities $(40 \mu \mathrm{g})$ of protein were separated by $10 \%$ sodium dodecyl sulphate-polyacrylamide gel electrophoresis (Wuhan Boster Biological Technology, Ltd.) and blotted onto polyvinylidene fluoride (PVDF) membrane (Merck Millipore, Bedford, MA, USA). The PVDF membrane was blocked for nonspecific protein binding with Tris-buffered saline/Tween-20 (TBST; Guangzhou Whiga Technology Co., Ltd.) and 5\% non-fat milk (Guangzhou Whiga Technology Co., Ltd.) at room temperature for $2 \mathrm{~h}$. Then, the membrane was incubated overnight at $4^{\circ} \mathrm{C}$ with primary goat anti-TRPM7 (1:500; Abcam, Cambridge, UK) and primary mouse anti- $\beta$-actin (1:1,000; Sigma-Aldrich, St. Louis, MO, USA) monoclonal antibodies. Next, the membranes were washed with TBST, incubated with HRP-conjugated rabbit anti-goat $\operatorname{IgG}(1: 500)$ and rabbit anti-mouse $\operatorname{IgG}(1: 1,000)$ secondary antibodies (Cell Signaling Technology, Inc.) for $1 \mathrm{~h}$, and then washed three times with TBST. The proteins were detected using an enhanced chemiluminescence system (a SignalBoost ${ }^{\mathrm{TM}}$ Immunoreaction Enhancer kit; Merck Millipore).

Detection of TRPM7 protein levels in ASMCs using immunofluorescence. ASMCs were fixed in cold acetone $\left(4^{\circ} \mathrm{C}\right)$ for $5 \mathrm{~min}$ and washed with $0.01 \mathrm{~mol} / \mathrm{l} \mathrm{PBS}$ (Guangzhou Whiga Technology Co., Ltd.) and immersed in 0.3\% Triton X-100 (Guangzhou Whiga Technology Co.,Ltd.) in PBS.Subsequently, ASMCs were blocked with 1\% BSA in PBS for $1 \mathrm{~h}$ at room temperature and incubated with primary monoclonal goat anti-TRPM7 antibody (1:100; Abcam) in PBS containing 3\% BSA for $24 \mathrm{~h}\left(4^{\circ} \mathrm{C}\right)$. Following a wash with PBS at $4^{\circ} \mathrm{C}$, ASMCs were labeled with the fluorescein isothiocyanate-conjugated secondary monoclonal donkey anti-goat IgG antibody (1:100; Jackson ImmunoResearch Laboratories, Baltimore, MA, USA) $1 \mathrm{~h}$ at room temperature. The nuclei of ASMCs were stained with Hoechst stain (Beyotime Institute of Biotechnology, Shanghai, China).

Design of shRNA against rat TRPM7. Short hairpin RNA (shRNA) targeting the rat TRPM7 gene (TRPM7-shRNA) was designed and synthesized by Guangzhou Forevergen Co., Ltd. (Guangzhou, China) and the sequences were as follows: Forward, 5'-GATCCCCGTCGTTTCTTCCAGAGGTGTTCA AGAGACACCTCTGGA AGA AACGACTTTTTA-3' and reverse, 5'-AGCTTAAAAAGTCGTTTCTTCCAGAGGTGT CTCTTGAACACCTCTGGAAGAAACGACGGG-3'. The control shRNA contained scrambled sequences (scramble-shRNA) as follows: Forward, 5'-GATCCCCGC CAGCTTAGCACTGACTCTTCAAGAGAGAGTCAGTGCT AAGCTGGCTTTTTA-3' and reverse, 5'-AGCTTAAAAAGC CAGCTTAGCACTGACTCTCTCTTGAAGAGTCAGTGCT AAGCTGGCGGG-3'.

Generation of lentivirus vectors and transduction of ASMCs. The lentivirus vectors were constructed as previously described (17). Briefly, 293T human kidney cells (Invitrogen; Thermo Fisher Scientific) in 10-cm culture dishes were cotransfected with $10 \mu \mathrm{g}$ pLV vector, $4.8 \mu \mathrm{g}$ pGag-Pol, $1.8 \mu \mathrm{g}$ pRev and $2.7 \mu \mathrm{g}$ pMDG (Guangzhou Forevergen Co., Ltd.) using Lipofectamine 2000 reagent (Invitrogen; Thermo Fisher Scientific, Inc.). The supernatants were collected 48 and $72 \mathrm{~h}$ after transfection, filtered through a $0.4-\mu \mathrm{m}$ membrane and the viruses were concentrated using an Amicon Ultra-15 $100 \mathrm{kDa}$ filter (Merck Millipore). Transduction of ASMCs with lentivirus vectors was performed in the presence of $10 \mu \mathrm{g} / \mathrm{ml}$ polybrene (Sigma-Aldrich). Using pLV vectors with puromycin marker (a coding sequence of the lentivirus vector, obtained from Guangzhou Forevergen Co., Ltd.), cells were selected with $2 \mu \mathrm{g} / \mathrm{ml}$ puromycin (Merck Millipore) following transduction for $24 \mathrm{~h}$. The floating cells were removed, and the remaining attached cells were analyzed and collected for further experiments.

$\left[{ }^{3} \mathrm{H}\right]$-thymidine incorporation assay. ASMCs were plated in 24-well cluster plates at a density of $1 \times 10^{5}$ cells/well in a medium containing $10 \% \mathrm{FCS}$ and grown to $95 \%$ confluence. ASMCs were stimulated with CSE (5 or $15 \%$ ) or TNF- $\alpha$ ( $1 \mathrm{ng} / \mathrm{ml}$; Sigma-Aldrich) for $24 \mathrm{~h}$. Then the cells were cultured with $\left[{ }^{3} \mathrm{H}\right]$-thymidine $(0.25 \mu \mathrm{Ci} / \mathrm{ml}$; GE Healthcare Life Sciences, Chalfont, UK) for $24 \mathrm{~h}$, harvested onto glass-fiber filters (Merck Millipore), and washed twice with PBS and twice with ice-cold 5\% trichloroacetic acid (Guangzhou Whiga Technology Co., Ltd.). Subsequently, the cells were dissolved in $0.5 \mathrm{ml} \mathrm{NaOH}(1 \mathrm{M})$. Incorporated $\left[{ }^{3} \mathrm{H}\right]$-thymidine was quantified by liquid-scintillation counting (Beckman Coulter Inc., Brea, CA, USA).

Cell number determination. ASMCs were plated in 24-well cluster plates at a density of $1 \times 10^{5}$ cells/well in medium containing $10 \%$ FCS and grown to $95 \%$ confluence. Then the cells were stimulated with CSE (5 or $15 \%)$ or TNF- $\alpha(1 \mathrm{ng} / \mathrm{ml})$ for $24 \mathrm{~h}$. ASMCs were harvested and viable cells were counted 
in duplicate, using a hemocytometer (Guduo Biotechnology Co., Ltd., Shanghai, China). Trypan blue exclusion assay was performed by mixing $80 \mu \mathrm{l}$ cell suspension and $20 \mu 10.4 \%$ Trypan Blue Solution (Sigma-Aldrich) for $2 \mathrm{~min}$. Blue cells were counted as dead cells and the cells that did not absorb the dye were counted as living cells.

Measurement of IL-8 in ASMCs. ASMCs were plated in 24-well cluster plates, washed with PBS and stimulated with CSE (5 or $15 \%$ ) for $24 \mathrm{~h}$ or TNF- $\alpha(1 \mathrm{ng} / \mathrm{ml})$ for $1 \mathrm{~h}$. Release of IL-8 in the ASMCs culture supernatants was measured using a specific IL-8 enzyme-linked immunosorbent assay (ELISA) kit (Sanquin, Amsterdam, Netherlands) according to the manufacturers' protocol.

Statistical analysis. Data are presented as mean \pm standard error of the mean. Statistical significance was determined by Student's $t$-test for unpaired observations or one-way analysis of variance followed by Bonferroni's post-hoc test for independent observations. $\mathrm{P}<0.05$ was considered to indicate a statistically significant difference.

\section{Results}

ASMC proliferation in rats exposed to cigarette smoke. The lung tissue of rats was collected for pathological analysis and $\alpha$-smooth muscle actin immunohistochemical staining. Morphological observations were performed under a light microscope (Fig. 1). The structure of the alveoli was mostly undamaged, the bronchioles were clear (i.e. there was no infiltration of inflammatory cells in bronchioles of control rats without CSE), and the bronchioles of normal control rats exhibited eumorphism in terms of their cell structure and histology. By contrast, pulmonary emphysema manifested as alveolar wall thinning, alveolar structure disruption, and alveolar space enlargement and fusion were observed in rats that had been exposed to cigarette smoke. Additionally, bronchial epithelial hyperplasia, submucosal inflammatory cell infiltration, and airway wall and ASM thickening were observed in rats exposed to cigarette smoke.

An increase in ASM mass was observed in rats exposed to cigarette smoke when compared with normal rats [the ratio of the ASM area to the total airway area was $0.1645 \pm 0.01016 \mathrm{vs}$. $0.0479 \pm 0.00889(\mathrm{n}=8)$ for CSE rats compared with normal rats; respectively; $\mathrm{t}=70.139 ; \mathrm{P}<0.001]$.

TRPM7 is upregulated in ASMCs from smoke-exposed rats. The expression of TRPM7 in primary ASMCs was detected by RT-PCR, western blot analysis and immunofluorescence. As indicated by Fig. 2, the TRPM7 mRNA level was elevated in ASMCs of smoke-exposed rats when compared with normal rats. Furthermore, the western blot analysis indicated increased TRPM7 protein levels in ASMCs in smoke-exposed rats compared with normal rats (Fig. 3). Additionally, immunofluorescence demonstrated increased expression levels of TRPM7 proteins in ASMCs from smoke-exposed rats when compared with normal rats (Fig. 4).

Silencing of TRPM7 in ASMCs by TRPM7-shRNA lentivirus vector. TRPM7 protein expression was detected by western blotting in ASMCs infected with the TRPM7-shRNA lentivirus vector. As indicated by Fig. 5, treatment with TRPM7-shRNA lentivirus vector resulted in a significant decrease in TRPM7 protein expression.

Upregulation of TRPM7 augments proliferation of ASMCs from smoke-exposed rats. ASMCs were stimulated with CSE $(5 \%$ or $15 \%)$ or TNF- $\alpha(1 \mathrm{ng} / \mathrm{ml})$ for $24 \mathrm{~h}$. To assess the proliferation of ASMCs, DNA synthesis and cell number of ASMCs were determined by $\left[{ }^{3} \mathrm{H}\right]$-thymidine incorporation assay and with a hemocytometer, respectively. As indicated by Fig. 6, stimulation with CSE (5\%) did not induce increased DNA synthesis or ASMC number. However, treatment with TRPM7-shRNA lentivirus vector significantly reduced methyl- $\left[{ }^{3} \mathrm{H}\right]$-thymidine incorporation and the cell number of ASMCs compared with ASMCs that were not treated with the TRPM7-shRNA lentivirus vector. These observations indicated that TRPM7 is required for ASMC proliferation.

Stimulation with CSE (15\%) induced significantly increased DNA synthesis and ASMC number, which was not alleviated by treatment with TRPM7-shRNA lentivirus vector (Fig. 7). When compared with ASMCs from normal rats, the CSE (15\%)-induced increases of methyl-[ $\left.{ }^{3} \mathrm{H}\right]$-thymidine incorporation and cell number were significantly enhanced in ASMCs from smoke-exposed rats, as demonstrated by greater expression levels of TRPM7. Treatment with TRPM7-shRNA lentivirus vector reduced methyl- $\left[{ }^{3} \mathrm{H}\right]$-thymidine incorporation and cell number of ASMCs. These results indicated that upregulation of TRPM7 augmented proliferation of ASMCs induced by CSE (15\%) in smoke-exposed rats. However, in ASMCs treated with TRPM7-shRNA lentivirus vector, stimulation with CSE (15\%) induced significantly increased cell number of ASMCs from smoke-exposed rats when compared with normal rats.

As indicated by Fig. 8, stimulation with TNF- $\alpha(1 \mathrm{ng} / \mathrm{ml})$ led to increased DNA synthesis in ASMCs, this increase was enhanced significantly in ASMCs from smoke-exposed rats with higher expression levels of TRPM7. However, stimulation with TNF- $\alpha(1 \mathrm{ng} / \mathrm{ml})$ induced a significant increase in ASMC number in smoke-exposed rats, but not in ASMC number in normal rats. Treatment with TRPM7-shRNA lentivirus vector reduced methyl- $\left[{ }^{3} \mathrm{H}\right]$-thymidine incorporation and cell number of ASMCs. This indicated that upregulation of TRPM7 augmented proliferation of ASMCs induced by TNF- $\alpha(1 \mathrm{ng} / \mathrm{ml})$ in smoke-exposed rats. However, increased methyl- $\left[{ }^{3} \mathrm{H}\right]$-thymidine incorporation and cell number of ASMCs from smoke-exposed rats induced by TNF- $\alpha$ was not completely inhibited by treatment with TRPM7-shRNA lentivirus vector.

Upregulation of TRPM7 augments IL-8 secretion in ASMCs from smoke-exposed rats. ASMCs were stimulated with CSE $(5 \%$ or $15 \%)$ for $24 \mathrm{~h}$ or TNF- $\alpha(1 \mathrm{ng} / \mathrm{ml})$ for $1 \mathrm{~h}$ and the IL- 8 release was determined using an ELISA. Stimulation with CSE (5\%) did not increase IL-8 release significantly and treatment with TRPM7-shRNA lentivirus vector did not affect IL-8 release in the ASMCs.

Stimulation with CSE (15\%) or TNF- $\alpha$ (1 ng/ml) significantly increased the secretion of IL- 8 in ASMCs was not inhibited by treatment with TRPM7-shRNA lentivirus vector 

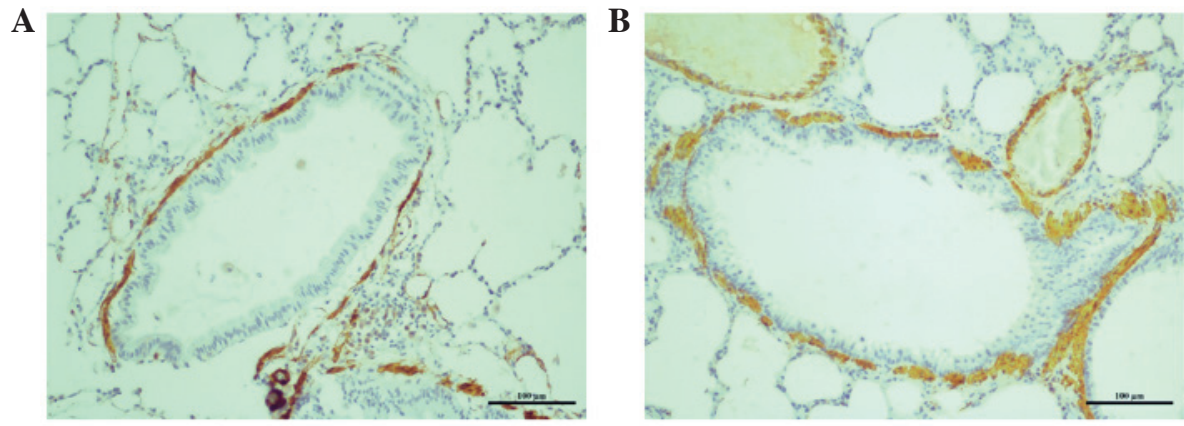

Figure 1. $\alpha$-smooth muscle actin immunohistochemical staining of rat bronchioles (magnification, x200). (A) Structure of bronchioles was undamaged and eumorphism in terms of cell structure and histology was exhibited in normal rats. (B) Pulmonary emphysema, bronchial epithelial hyperplasia, submucosal inflammatory cell infiltration, and airway wall and airway smooth muscle thickening were observed in rats exposed to cigarette smoke. Scale bar, $100 \mu \mathrm{m}$.

A

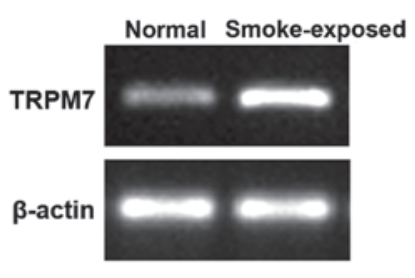

B

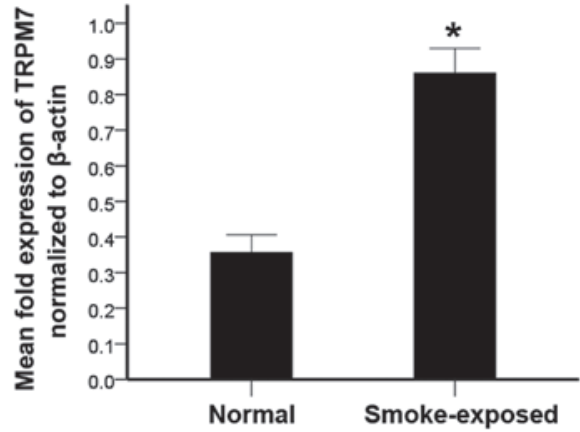

Figure 2. Expression of TRPM7 mRNA detected by RT-PCR. (A) TRPM7 mRNA levels in ASMCs of normal and smoke-exposed rats. The gels are representative of at least three independent experiments. (B) Relative optical density of the RT-PCR band as percentage values (TRPM7/ $\beta$-actin) in the samples. ${ }^{*} \mathrm{P}<0.05$ vs. ASMCs of normal rats. Data are presented as the mean \pm standard error of the mean. TRPM7, transient receptor potential cation channel subfamily M member 7; RT-PCR, reverse transcription-polymerase chain reaction; ASMCs, airway smooth muscle cells.

A

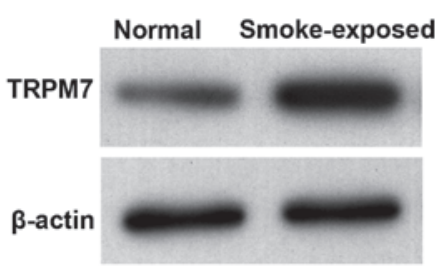

B

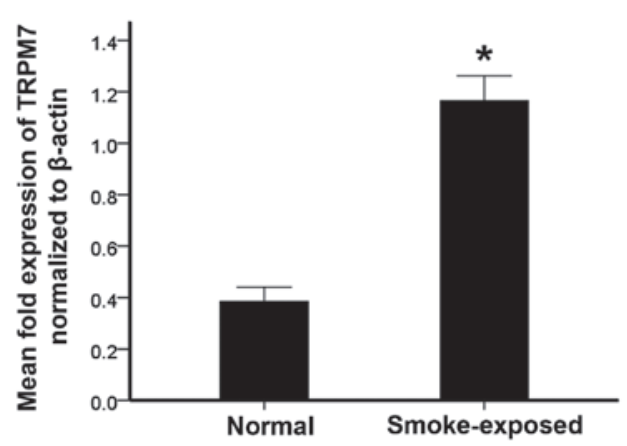

Figure 3. Expression of TRPM7 protein levels detected by western blot assay. (A) TRPM7 protein levels in ASMCs of normal and smoke-exposed rats. The gels are representative of at least three independent experiments. (B) Relative optical density of the western blotting bands as percentage values (TRPM7/ $\beta$-actin) in the samples. "P<0.05 vs. ASMCs from normal rats. Data are presented as the mean \pm standard error of the mean. TRPM7, transient receptor potential cation channel subfamily M member 7;. ASMCs, airway smooth muscle cells.

(Figs. 9 and 10). Compared with ASMCs from normal rats, the increase of IL- 8 secretion induced by CSE (15\%) or TNF- $\alpha$ was greater in ASMCs from smoke-exposed rats with higher levels of TRPM7 expression. Treatment with TRPM7-shRNA lentivirus vector reduced IL-8 release, which was induced by CSE (15\%) and TNF- $\alpha$ in ASMCs. These results indicated that upregulation of TRPM7 augmented CSE (15\%)- or TNF- $\alpha$-induced IL- 8 secretion in ASMCs from smoke-exposed rats. However, in ASMCs treated with the TRPM7-shRNA lentivirus vector, stimulation with CSE (15\%) or TNF- $\alpha$ also induced a significant increase in IL-8 secretion in ASMCs from smoke-exposed rats when compared with normal rats.

\section{Discussion}

The present study demonstrated that TRPM7 was upregulated in ASMCs from rats exposed to cigarette smoke. The TRP channel is a superfamily of ion channels that control the passage of various ions across membranes (11). These channels are homo- or heterotetramers formed by proteins, which contain 

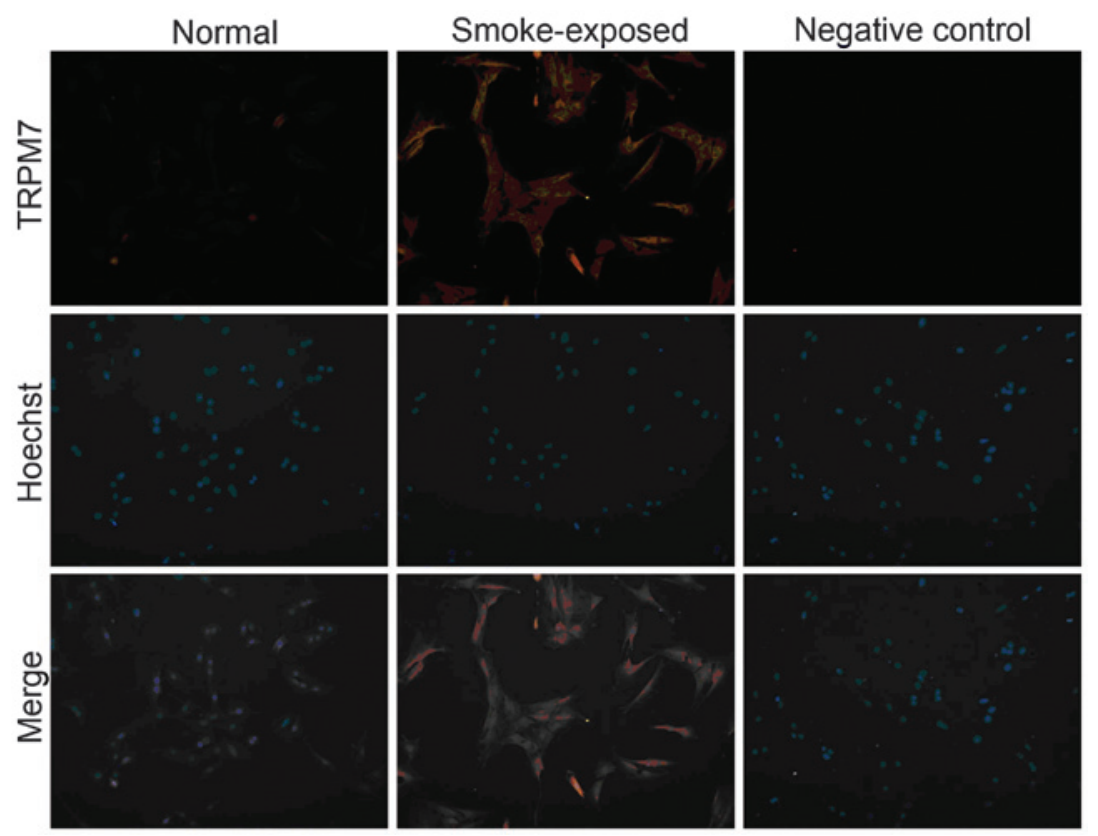

Figure 4. Expression of TRPM7 detected by immunofluorescence. Higher expression levels of TRPM7 were observed by immunofluorescence in the cell membranes of ASMCs from smoke-exposed rats when compared with those of normal rats. Magnification, x100. TRPM7, transient receptor potential cation channel subfamily M member 7;. ASMCs, airway smooth muscle cells.

six putative transmembrane domains and a pore-forming loop between the fifth and sixth segments. TRPM7 is a widely expressed member of the TRP superfamily. Previous studies have indicated that TRPM7 is expressed in various cell types, including lymphocytes (20), neurons (21), vascular smooth muscle cells (22), vascular endothelia (23), mast cells (24), fibroblasts (25), kidney cells (26) and adipocytes (27). In the present study, RT-PCR, western blot assays and immunofluorescence demonstrated that TRPM7 was expressed in ASMCs from normal rats and the expression levels of TRPM7 were markedly higher in ASMCs from smoke-exposed rats.

The results of the current study identified that upregulation of TRPM7 augmented proliferation in ASMCs from smoke-exposed rats. The function of TRPM7 in cellular proliferation varies between different cell types. In certain types of cells, TRPM7 exhibits a cell death function; for example, TRPM7 leads to cell death in anoxic neurons (21). However, TRPM7 is also required for cell survival and proliferation in various cell types. Previously, it was reported that TRPM7 suppression by retrovirus-mediated siRNA targeting the TRPM7 gene decreased the survival rate of RBL-2H3 cells (28). Additionally, TRPM7 is required for the proliferation of various types of normal and cancer cell, including human mast (24), B lymphocyte (20), human head and neck carcinoma (29), breast cancer (30), hepatocellular carcinoma (31), gastric cancer (32) and prostate cancer (33) cells. Consistent with the majority of results regarding the underlying mechanisms of cellular proliferation, in the current study, silencing of TRPM7 reduced DNA synthesis and cell number of ASMCs, and upregulation of TRPM7 augmented cell proliferation in ASMCs from rats exposed to cigarette smoke.

To the best of our knowledge, this is the first study regarding the importance of TRPM7 in cytokine secretion by ASMCs. In our previous study, it was determined that knockdown
A

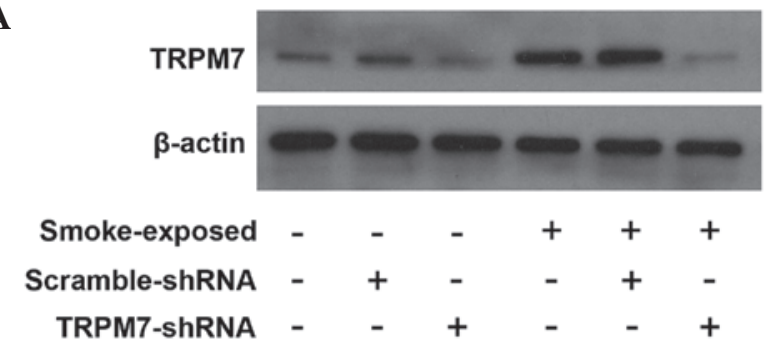

B

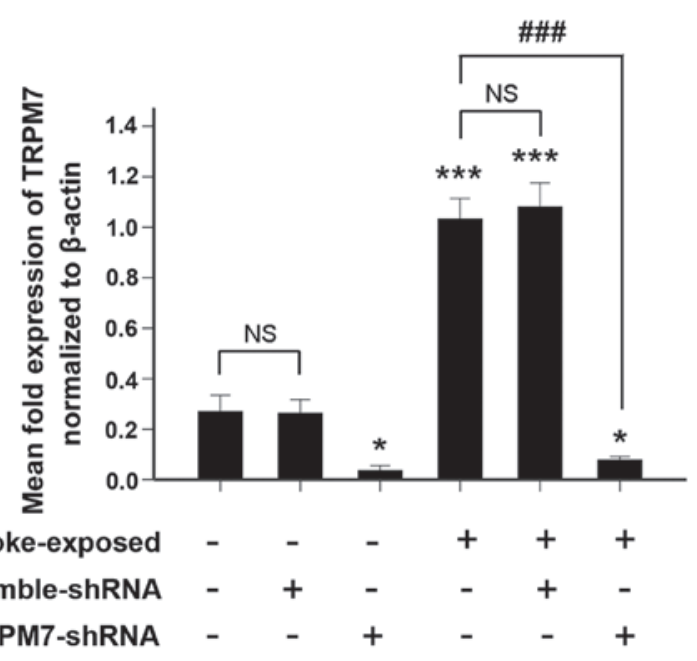

Figure 5. Silencing of TRPM7 in ASMCs. (A) Expression levels of TRPM7 protein in ASMCs from normal and smoke-exposed rats infected with scramble-shRNA lentivirus vector or TRPM7-shRNA lentivirus vector was detected by western blot assays. The gels are representative of at least three independent experiments. (B) Relative optical density of the western blotting bands as percentage values (TRPM7/ $\beta$-actin) in the samples. ${ }^{\text {NS }} \mathrm{P}>0.05$; ${ }^{*} \mathrm{P}<0.05$ vs. ASMCs from normal rats without lentivirus vector treatment; ${ }^{* * *} \mathrm{P}<0.001$ vs. ASMCs from normal rats without lentivirus vector treatment; ${ }^{\# \#} \mathrm{P}<0.001$ vs. ASMCs from smoke-exposed rats without lentivirus vector treatment. Data are presented as the mean \pm standard error of the mean. TRPM7, transient receptor potential cation channel subfamily M member 7; NS, not significant; shRNA, short hairpin RNA; ASMCs, airway smooth muscle cells. 


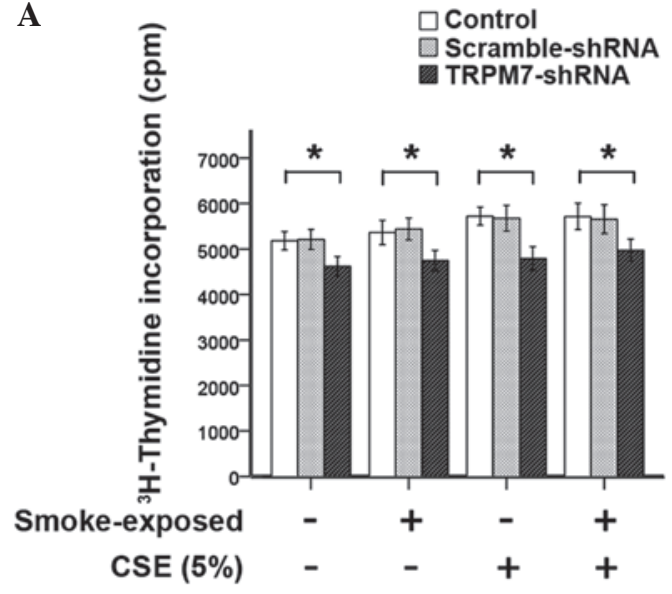

B

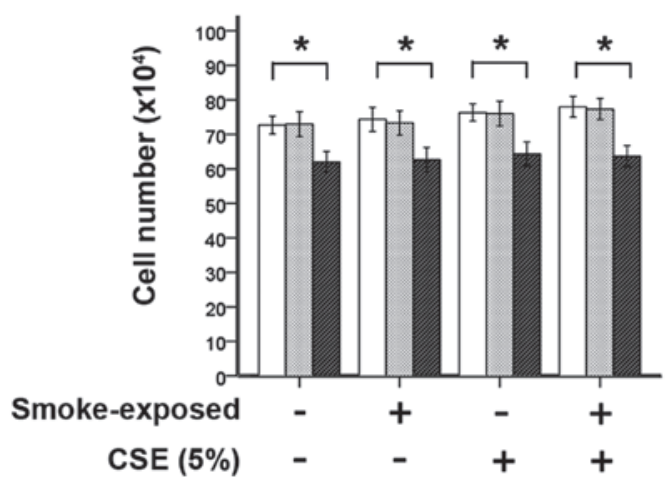

Figure 6. Proliferation of ASMCs induced by CSE (5\%). (A) DNA synthesis in ASMCs stimulated with CSE (5\%) for $24 \mathrm{~h}$ was assessed by methyl- $\left[{ }^{3} \mathrm{H}\right]$-thymidine incorporation. (B) Cell number of ASMCs stimulated with CSE (5\%) for $24 \mathrm{~h}$ was detected by hemocytometer. Data are presented as the mean \pm standard error of the mean of eight independent experiments. " $\mathrm{P}<0.05$ vs. ASMCs without lentivirus vector treatment. CSE, cigarette smoke extract; TRPM7, transient receptor potential cation channel subfamily M member 7; shRNA, short hairpin RNA; ASMCs, airway smooth muscle cells.

of TRPM7 reduced the release of cytokines in rat bone marrow-derived mast cells (17). Therefore, the present study determined that silencing of TRPM7 with TRPM7-shRNA lentivirus vector reduced IL-8 release in ASMCs induced by CSE (15\%) and TNF- $\alpha$ in ASMCs from rats exposed to cigarette smoke. Furthermore, the increase of IL- 8 secretion induced by CSE and TNF- $\alpha$ was enhanced in ASMCs from rats exposed to cigarette smoke, as demonstrated by higher expression levels of TRPM7. This suggests that upregulation of TRPM7 augmented the release of IL-8 in ASMCs from rats exposed to cigarette smoke. As IL-8 is important in neutrophil recruitment, the upregulation of TRPM7 in ASMCs from rats exposed to cigarette smoke may contribute to the inflammatory response of the airway.

The present study investigated the proliferation of ASMCs and IL- 8 release induced by TNF- $\alpha$ due to the association between cigarette smoke exposure and TNF- $\alpha$. The level of TNF- $\alpha$ is often associated with smoking status, systemic inflammation and airflow limitation in patients with COPD $(34,35)$. In animal models, mice with knocked-out TNF- $\alpha$ receptors did not develop an inflammatory response following acute cigarette smoke exposure (36). Furthermore, it was previously demonstrated that TNF- $\alpha$ accounts for the majority of inflam-
A
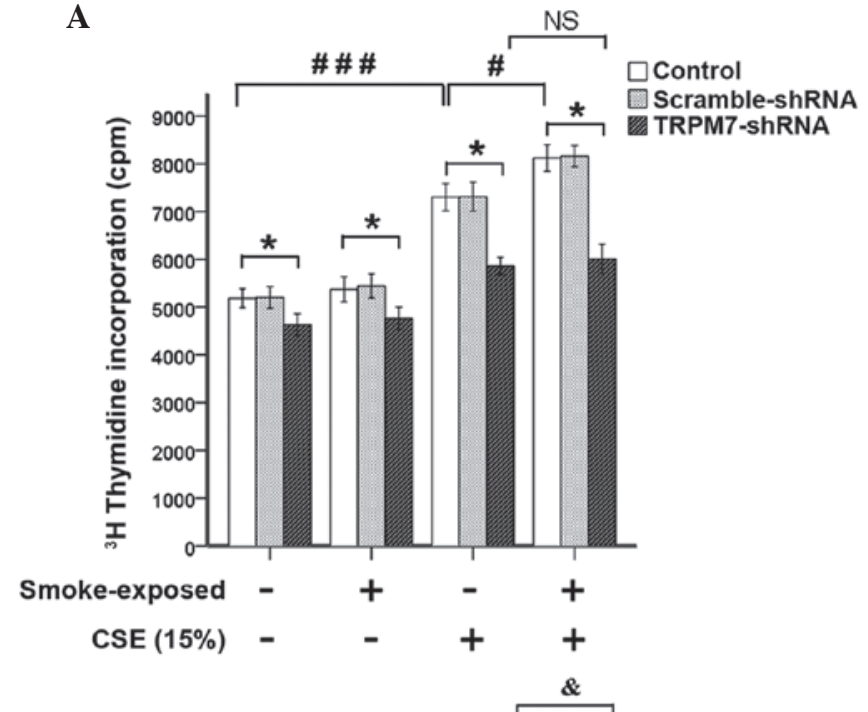

B

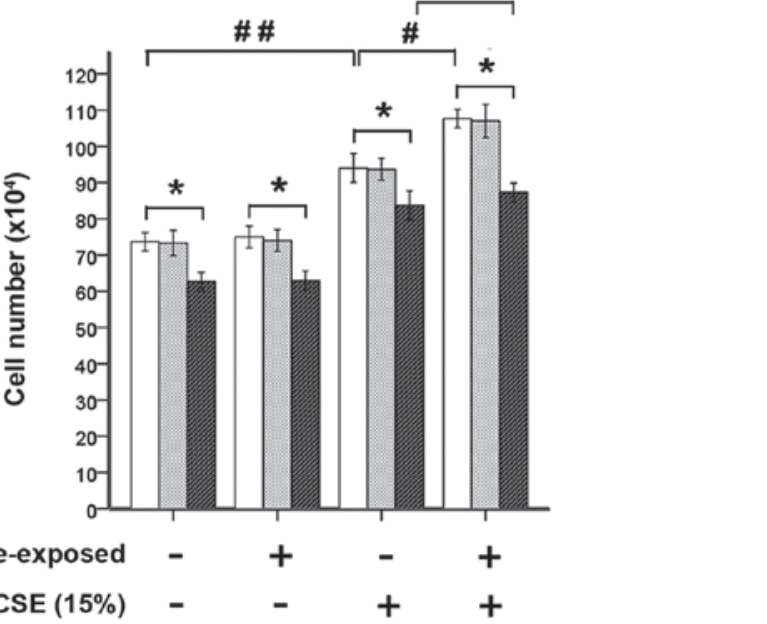

Figure 7. Proliferation of ASMCs induced by CSE (15\%). (A) DNA synthesis in ASMCs stimulated with CSE (15\%) for $24 \mathrm{~h}$ was assessed by methyl- $\left[{ }^{3} \mathrm{H}\right]$-thymidine incorporation. ${ }^{*} \mathrm{P}<0.05$ vs. ASMCs without lentivirus vector treatment; ${ }^{\# P} \mathrm{P}<0.05$ vs. ASMCs from normal rats with CSE (15\%) stimulation and without lentivirus vector treatment; ${ }^{\# \# \#} \mathrm{P}<0.001$ vs. ASMCs from normal rats without CSE (15\%) stimulation or lentivirus vector treatment; ${ }^{\mathrm{NS}} \mathrm{P}>0.05$ vs. ASMCs from normal rats with CSE (15\%) stimulation and lentivirus vector treatment. (B) Cell number of ASMCs stimulated with CSE $(15 \%)$ for $24 \mathrm{~h}$ was detected by hemocytometer. ${ }^{*} \mathrm{P}<0.05$ vs. ASMCs without lentivirus vector treatment; ${ }^{\#} \mathrm{P}<0.05$ vs. ASMCs from normal rats with CSE (15\%) stimulation and without lentivirus vector treatment; ${ }^{\# \#} \mathrm{P}<0.01$ vs. ASMCs from normal rats without CSE $(15 \%)$ stimulation or lentivirus vector treatment; ${ }^{\circledR} \mathrm{P}<0.05$ vs. ASMCs from normal rats with CSE $(15 \%)$ stimulation and lentivirus vector treatment. Data are presented as the mean \pm standard error of the mean of eight independent experiments. CSE, cigarette smoke extract; TRPM7, transient receptor potential cation channel subfamily M member 7; shRNA, short hairpin RNA; ASMCs, airway smooth muscle cells; NS, not significant.

matory cell infiltration in a mouse model with 6-month smoke exposure (37). However, the mitogenic effect of TNF- $\alpha$ on ASMCs is controversial. A previous study reported that TNF- $\alpha$ promotes ASMC proliferation, which was mediated via the phosphatidylinositol 3-kinase signaling pathway, and the p38 and extracellular signal-regulated kinase 1/2 mitogen-activated protein kinase (MAPK) signaling pathway (5). Furthermore, it was previously proposed that TNF- $\alpha$ did not induce the proliferation of ASMCs (38) and may inhibit proliferation induced by other growth factors (39). This may be due to differences in species used for the experiments, the concentration of TNF- $\alpha$, 


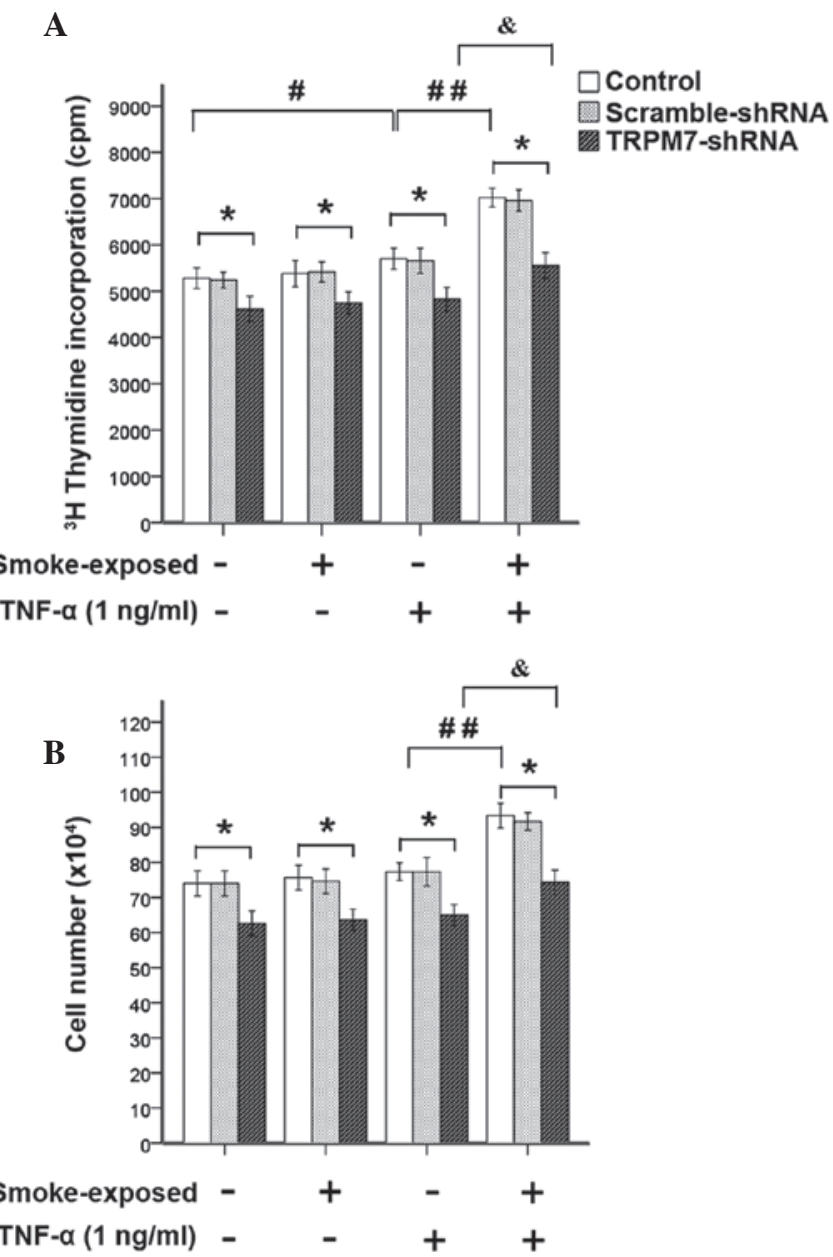

Figure 8. Proliferation of ASMCs induced by TNF- $\alpha$. (A) DNA synthesis in ASMCs stimulated with TNF- $\alpha(1 \mathrm{ng} / \mathrm{ml})$ for $24 \mathrm{~h}$ was assessed by methyl- $\left[{ }^{3} \mathrm{H}\right]$-thymidine incorporation. ${ }^{*} \mathrm{P}<0.05$ vs. ASMCs without lentivirus vector treatment; ${ }^{\prime \prime} \mathrm{P}<0.05$ vs. ASMCs from normal rats without TNF- $\alpha$ stimulation or lentivirus vector treatment; ${ }^{\# \#} \mathrm{P}<0.01$ vs. ASMCs from normal rats with TNF- $\alpha$ stimulation and without lentivirus vector treatment; ${ }^{\&} \mathrm{P}<0.05$ vs. ASMCs from normal rats with TNF- $\alpha$ stimulation and lentivirus vector treatment. (B) Cell number of ASMCs stimulated with TNF- $\alpha$ $(1 \mathrm{ng} / \mathrm{ml})$ for $24 \mathrm{~h}$ was detected by hemocytometer. ${ }^{*} \mathrm{P}<0.05$ vs. ASMCs without lentivirus vector treatment; ${ }^{\# \#} \mathrm{P}<0.01$ vs. ASMCs from normal rats with TNF- $\alpha$ stimulation and without lentivirus vector treatment; ${ }^{\circledR} \mathrm{P}<0.05$ vs. ASMCs from normal rats with TNF- $\alpha$ stimulation and lentivirus vector treatment. Data are presented as the mean \pm standard error of the mean of eight independent experiments. TRPM7, transient receptor potential cation channel subfamily M member 7; shRNA, short hairpin RNA; TNF- $\alpha$, tumor necrosis factor- $\alpha$; ASMCs, airway smooth muscle cells.

exposure duration and culture medium. In the present study, a positive mitogenic effect of TNF- $\alpha$ on ASMCs was observed and the upregulation of TRPM7 led to a proliferative effect of TNF- $\alpha$. The underlying mechanism of TRPM7 regulating the proliferation of ASMCs may contribute to a potential interaction between its distinctive serine/threonine protein kinase domain, and the PI3K and MAPK signaling pathway, which consists of a cascade reaction of serine/threonine kinases (40); however, further research is required to elucidate this further.

In the current study; however, treatment with TRPM7-shRNA lentivirus vector did not completely inhibit the effect of cell proliferation and IL-8 secretion that was induced by CSE (15\%) or TNF- $\alpha$. Stimulation with CSE $(15 \%)$ or TNF- $\alpha$ increased cell proliferation and IL-8 secre-

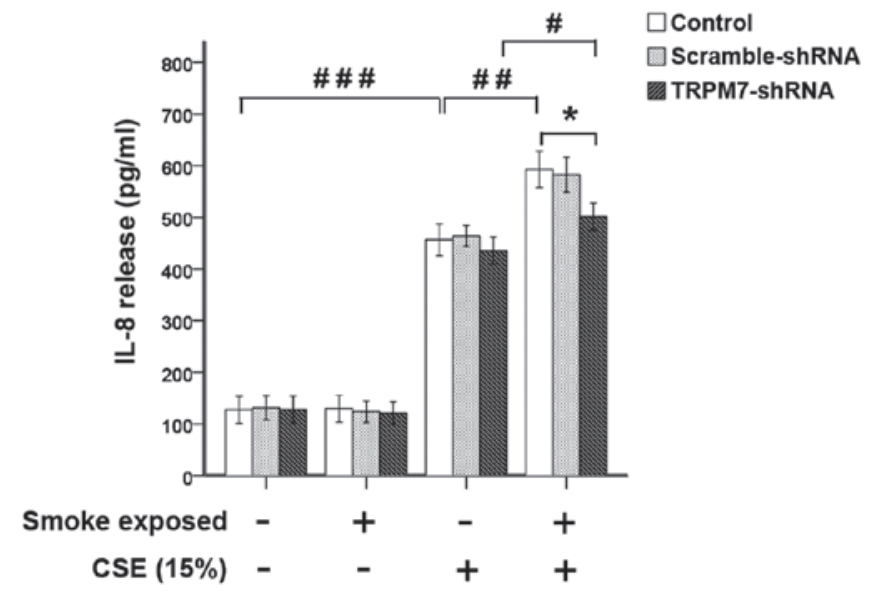

Figure 9. Secretion of IL-8 in ASMCs induced by CSE (15\%). The secretion of IL-8 in ASMCs stimulated by CSE (15\%) for $24 \mathrm{~h}$ was determined with enzyme-linked immunosorbent assay. ${ }^{*} \mathrm{P}<0.05$ vs. ASMCs from smoke-exposed rats with CSE (15\%) stimulation and without lentivirus vector treatment; ${ }^{*} \mathrm{P}<0.05$ vs. ASMCs from normal rats with CSE $(15 \%)$ stimulation and lentivirus vector treatment; ${ }^{\# \#} \mathrm{P}<0.01$ vs. ASMCs from normal rats with CSE $(15 \%)$ stimulation and without lentivirus vector treatment; ${ }^{\# \# /} \mathrm{P}<0.001$ vs. ASMCs from normal rats without CSE $(15 \%)$ stimulation or lentivirus vector treatment. Data are presented as the mean \pm standard error of the mean of eight independent experiments. CSE, cigarette smoke extract; TRPM7, transient receptor potential cation channel subfamily M member 7; shRNA, short hairpin RNA; IL-8, interleukin-8; ASMCs, airway smooth muscle cells.

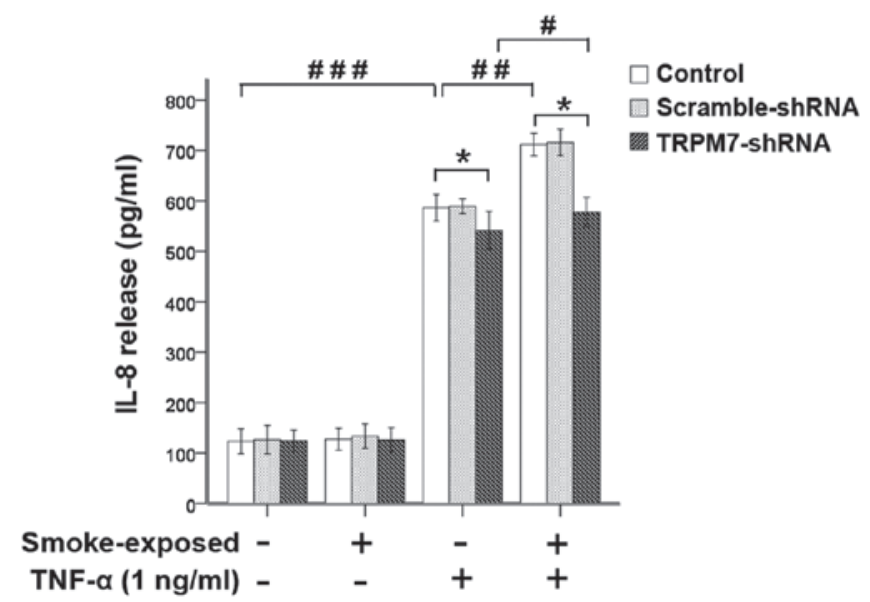

Figure 10. Secretion of IL- 8 in ASMCs was induced by TNF- $\alpha$. This was determined using enzyme-linked immunosorbent assay. " $\mathrm{P}<0.05$ vs. ASMCs from smoke-exposed rats with TNF- $\alpha$ stimulation and without lentivirus vector treatment; " $\mathrm{P}<0.05$ vs. ASMCs from normal rats with TNF- $\alpha$ stimulation and lentivirus vector treatment; ${ }^{\# /} \mathrm{P}<0.01$ vs. ASMCs from normal rats with TNF- $\alpha$ stimulation and without lentivirus vector treatment; ${ }^{\# \#} \mathrm{P}<0.001$ vs. ASMCs from normal rats without TNF- $\alpha$ stimulation or lentivirus vector treatment. Data are presented as the mean \pm standard error of the mean of eight independent experiments. IL-8, interleukin-8; TRPM7, transient receptor potential cation channel subfamily M member 7; shRNA, short hairpin RNA; TNF- $\alpha$, tumor necrosis factor- $\alpha$; ASMCs, airway smooth muscle cells.

tion in ASMCs from smoke-exposed rats when compared with normal rats in the presence of TRPM7-shRNA lentivirus vector treatment. This indicated that there is an alternative mechanism inducing the response to cigarette smoke or TNF- $\alpha$ in ASMCs.

In conclusion, the present study revealed that TRPM7 expression levels were elevated in ASMCs from rats exposed to 
cigarette smoke, and that upregulation of TRPM7 augmented cell proliferation and IL-8 secretion in ASMCs from smoke-exposed rats. ASMC proliferation and IL-8 secretion are considered to be important in the development of COPD; therefore, the current study indicates that TRPM7 may be a potential target for the treatment of COPD.

\section{Acknowledgements}

The present study was supported by the National Science Foundation of China (grant nos. 81000015 and 81370120).

\section{References}

1. Vestbo J,Hurd SS, Agustí AG, Jones PW, Vogelmeier C, Anzueto A Barnes PJ, Fabbri LM, Martinez FJ, Nishimura M, et al: Global strategy for the diagnosis, management and prevention of chronic obstructive pulmonary disease: gold executive summary. Am J Respir Crit Care Med 187: 347-365, 2013.

2. Saetta M, Di Stefano A, Turato G, Facchini FM, Corbino L, Mapp CE, Maestrelli P, Ciaccia A and Fabbri LM: CD8+ T-lymphocytes in peripheral airways of smokers with chronic obstructive pulmonary disease. Am J Respir Crit Care Med 157: 822-826, 1998.

3. Hogg JC, Chu F, Utokaparch S, Woods R, Elliott WM Buzatu L, Cherniack RM, Rogers RM, Sciurba FC, Coxson HO and Paré PD: The nature of small-airway obstruction in chronic obstructive pulmonary disease. N Engl J Med 350: 2645-2653, 2004.

4. Chung KF: The role of airway smooth muscle in the pathogenesis of airway wall remodeling in chronic obstructive pulmonary disease. Proc Am Thorac Soc 2: 347-354; discussion 371-372, 2005.

5. Stamatiou R, Paraskeva E, Gourgoulianis K, Molyvdas PA and Hatziefthimiou A: Cytokines and growth factors promote airway smooth muscle cell proliferation. ISRN Inflamm 2012: 731472, 2012.

6. Pera T, Gosens R, Lesterhuis AH, Sami R, van der Toorn M, Zaagsma $\mathbf{J}$ and Meurs H: Cigarette smoke and lipopolysaccharide induce a proliferative airway smooth muscle phenotype. Respir Res 11: 48, 2010.

7. Howarth PH, Knox AJ, Amrani Y, Tliba O, Panettieri RA Jr and Johnson M: Synthetic responses in airway smooth muscle. J Allergy Clin Immunol 114 (Suppl 2): S32-S50, 2004.

8. Manetsch M, Seidel P, Heintz U, Che W, Hughes JM, Ge Q, Sukkar MB and Ammit AJ: TLR2 ligand engagement upregulates airway smooth muscle TNF $\alpha$-induced cytokine production. Am J Physiol Lung Cell Mol Physiol 302: L838-L845, 2012.

9. Baarsma HA, Meurs H, Halayko AJ, Menzen MH, Schmidt M, Kerstjens HA and Gosens R: Glycogen synthase kinase-3 regulates cigarette smoke extract- and IL-1 $\beta$-induced cytokine secretion by airway smooth muscle. Am J Physiol Lung Cell Mol Physiol 300: L910-L919, 2011.

10. Gosens R, Rieks D, Meurs H, Ninaber DK, Rabe KF, Nanninga J, Kolahian S, Halayko AJ, Hiemstra PS and Zuyderduyn S: Muscarinic M3 receptor stimulation increases cigarette smoke-induced IL-8 secretion by human airway smooth muscle cells. Eur Respir J 34: 1436-1443, 2009.

11. Clapham DE: TRP channels as cellular sensors. Nature 426: 517-524, 2003

12. Schmitz C, Perraud AL, Johnson CO, Inabe K, Smith MK, Penner R, Kurosaki T, Fleig A and Scharenberg AM: Regulation of vertebrate cellular $\mathrm{Mg}^{2+}$ homeostasis by TRPM7. Cell 114: 191-200, 2003

13. Runnels LW, Yue L and Clapham DE: TRP-PLIK, a bifunctional protein with kinase and ion channel activities. Science 291: 1043-1047, 2001

14. Fonfria E, Murdock PR, Cusdin FS, Benham CD, Kelsell RE and McNulty S: Tissue distribution profiles of the human TRPM cation channel family. J Recept Signal Transduct Res 26: 159-178, 2006.

15. Kunert-Keil C, Bisping F, Krüger $\mathrm{J}$ and Brinkmeier $\mathrm{H}$ : Tissue-specific expression of TRP channel genes in the mouse and its variation in three different mouse strains. BMC Genomics 7: 159, 2006.
16. Visser D, Middelbeek J, van Leeuwen FN and Jalink K: Function and regulation of the channel-kinase TRPM7 in health and disease. Eur J Cell Biol 93: 455-465, 2014.

17. Huang L, Ng NM, Chen M, Lin X, Tang T, Cheng H, Yang C and Jiang S: Inhibition of TRPM7 channels reduces degranulation and release of cytokines in rat bone marrow-derived mast cells. Int J Mol Sci 15: 11817-11831, 2014.

18. Chen M, Shi JT, Lv ZQ, Huang LJ, Lin XL, Zhang W, Liang RY, Li YQ and Jiang SP: Triptolide inhibits TGF- $\beta 1$ induced proliferation and migration of rat airway smooth muscle cells by suppressing NF- $\kappa$ B but not ERK1/2. Immunology: Sep 29, 2014 (Epub ahead of print).

19. Chen M, Lv Z, Huang L, Zhang W, Lin X, Shi J, Zhang W, Liang $\mathrm{R}$ and Jiang S: Triptolide inhibits TGF- $\beta 1$-induced cell proliferation in rat airway smooth muscle cells by suppressing Smad signaling. Exp Cell Res 331: 362-368, 2015.

20. Sahni J, Tamura R, Sweet IR and Scharenberg AM: TRPM7 regulates quiescent/proliferative metabolic transitions in lymphocytes. Cell Cycle 9: 3565-3574, 2010.

21. Aarts M, Iihara K, Wei WL, Xiong ZG, Arundine M, Cerwinski W, MacDonald JF and Tymianski M: A key role for TRPM7 channels in anoxic neuronal death. Cell 115: 863-877, 2003.

22. Touyz RM: Transient receptor potential melastatin 6 and 7 channels, magnesium transport and vascular biology: Implications in hypertension. Am J Physiol Heart Circ Physiol 294: H1103-H1118, 2008.

23. Zeng Z, Inoue K, Sun H, Leng T, Feng X, Zhu L and Xiong ZG: TRPM7 regulates vascular endothelial cell adhesion and tube formation. Am J Physiol Cell Physiol 308: C308-C318, 2015.

24. Wykes RC, Lee M, Duffy SM, Yang W, Seward EP and Bradding P: Functional transient receptor potential melastatin 7 channels are critical for human mast cell survival. J Immunol 179: 4045-4052, 2007.

25. Yu M, Huang C, Huang Y, Wu X, Li X and Li J: Inhibition of TRPM7 channels prevents proliferation and differentiation of human lung fibroblasts. Inflamm Res 62: 961-970, 2013.

26. Meng Z, Cao R, Wang Y, Cao H, Liu T, Yang Z and Wang X: Suppression of renal TRPM7 may alleviate kidney injury in the renal transplantation. World J Urol 32: 1303-1311, 2014.

27. Che H, Yue J, Tse HF and Li GR: Functional TRPV and TRPM channels in human preadipocytes. Pflugers Arch 466: 947-959, 2014

28. Ng NM, Jiang SP and Lv ZQ: Retrovirus-mediated siRNA targeting TRPM7 gene induces apoptosis in RBL-2H3 cells. Eur Rev Med Pharmacol Sci 16: 1172-1178, 2012.

29. Jiang J, Li MH, Inoue K, Chu XP, Seeds J and Xiong ZG: Transient receptor potential melastatin 7-like current in human head and neck carcinoma cells: Role in cell proliferation. Cancer Res 67: 10929-10938, 2007.

30. Guilbert A, Gautier M, Dhennin-Duthille I, Haren N, Sevestre H and Ouadid-Ahidouch H: Evidence that TRPM7 is required for breast cancer cell proliferation. Am J Physiol Cell Physiol 297: C493-C502, 2009.

31. Mishra R, Rao V, Ta R, Shobeiri N and Hill CE: Mg2+and MgATP-inhibited and $\mathrm{Ca} 2+/$ calmodulin-sensitive TRPM7-like current in hepatoma and hepatocytes. Am J Physiol Gastrointest Liver Physiol 297: G687-G694, 2009.

32. Kim BJ, Kim SY, Lee S, Jeon JH, Matsui H, Kwon YK, Kim SJ and So I: The role of transient receptor potential channel blockers in human gastric cancer cell viability. Can J Physiol Pharmacol 90: 175-186, 2012.

33. Sun Y, Selvaraj S, Varma A, Derry S, Sahmoun AE and Singh BB: Increase in serum $\mathrm{Ca} 2+/ \mathrm{Mg} 2+$ ratio promotes proliferation of prostate cancer cells by activating TRPM7 channels. J Biol Chem 288: 255-263, 2013.

34. Tanni SE, Pelegrino NR, Angeleli AY, Correa C and Godoy I: Smoking status and tumor necrosis factor-alpha mediated systemic inflammation in COPD patients. J Inflamm (Lond) 7: $29,2010$.

35. Chiang $\mathrm{CH}$, Chuang $\mathrm{CH}$ and Liu SL: Transforming growth factor- $\beta 1$ and tumor necrosis factor- $\alpha$ are associated with clinical severity and airflow limitation of COPD in an additive manner. Lung 192: 95-102, 2014.

36. Churg A, Dai J, Tai H, Xie C and Wright JL: Tumor necrosis factor-alpha is central to acute cigarette smoke-induced inflammation and connective tissue breakdown. Am J Respir Crit Care Med 166: 849-854, 2002 
37. Churg A, Wang RD, Tai H, Wang X, Xie C and Wright JL: Tumor necrosis factor-alpha drives $70 \%$ of cigarette smoke-induced emphysema in the mouse. Am J Respir Crit Care Med 170: 492-498, 2004.

38. McKay S, Hirst SJ, Haas MB, de Jongste JC, Hoogsteden HC, Saxena PR and Sharma HS: Tumor necrosis factor-alpha enhances mRNA expression and secretion of interleukin- 6 in cultured human airway smooth muscle cells. Am J Respir Cell Mol Biol 23: 103-111, 2000.
39. Tliba O, Tliba S, Da Huang C, Hoffman RK, DeLong P, Panettieri RA Jr and Amrani Y: Tumor necrosis factor alpha modulates airway smooth muscle function via the autocrine action of interferon beta. J Biol Chem 278: 50615-50623, 2003

40. Yee NS, Kazi AA and Yee RK: Cellular and developmental biology of TRPM7 channel-kinase: Implicated roles in cancer. Cells 3:751-77, 2014. 